\title{
КУЛЬТУРА
}

ВОЛЬФ Александр Евгеньевич,

канд. ист. наук, старший научный сотрудник сектора новой и новейшей истории Ямало-Ненецкого окружного музейно-выставочного комплекса им. И. С. Шемановского (г. Салехард)

Электронная почта: wolf424@mail.ru

\section{К вопросу об исчезновении ритуального каннибализма в военной культуре коренных народов Западной Сибири}

В статье рассмотрен вопрос искоренения из военной культуры ханты и ненцев Западной Сибири такого обычая, как ритуальный каннибализм. Анализ литературных источников показал, что ханты прекратили его применять в первой половине XVII века, а ненцы - не ранее середины XVIII века. Отмирание этого обычая связано с введением Русским государством ясачной политики на территории Западной Сибири и объявлением зачинщиков междоусобиц государевыми изменниками. Эта мера, а также строительство острогов и начатая христианизация позволили установить относительный мир в северных районах Западной Сибири.

Цель исследования - определить хронологические рамки исчезновения сведений о военно-ритуальном каннибализме в культуре хантов (остяки в Российской империи) и ненцев (самоеды в Российской империи) Тобольского разряда и Сибирской губернии. Для этого сделан анализ текстов эпической и научной литературы, а также установлены причины, которые способствовали отмиранию этого обычая.

Возникшие в эпоху позднего палеолита религиозные верования, изменили и коллективное отношение к каннибализму. Если ранее его применяли исключительно для удовлетворения физиологических потребностей - голода, то с появлением религиозных обрядов и недостатка знаний начали использовать для умилостивления души умершего. Источником таких убеждений служила вера, что душа после смерти тела не умирает, а может начать беспокоить живых. Чтобы оградить себя от неприятностей, был даже создан культ поедания предков. Лица, участвовавшие в нём, считали, что, когда они съедят тело, душа покойника сольётся с душами живых родственников, и сделает их более сильными. Впоследствии этот культ был перенесён и на образ врага и не только с целью получения его силы (физической, психологической или умственной), но и для уничтожения его могущества [28, с. 247]. В представлении древних угров, душа-тень находилась в сердце, языке или печени, и если победитель съедал эти части тела побеждённого, он становился обладателем его души-тени, а также её качеств силы и мужества [25, с. 163]. Угры также верили, что душатень могла делиться на несколько частей. Поэтому, чтобы воины стали более мужественными, орган тела врага съедал не один, а несколько человек [17, с. 185; 16, с. 101]. Аналогичные военная культура, военно-ритуальный каннибализм, эnoc, богатырь, ханты, ненцы, ясак, воевода, Западная Сибирь, Русское государство

Для иитирования:

Вольф А. Е. К вопросу об исчезновении ритуального каннибализма в военной культуре коренных народов Западной Сибири // Известия Восточного института. 2021. № 1. C. 37-48. DOI https://doi.org/10.24866/25421611/2021-1/37-48 
представления существовали и у самодийцев [28, с. 247].

По-видимому, ритуальный каннибализм в военной культуре изначально существовал у всех народов эпохи архаики. Но в связи с тем, что учёные начали изучать первобытные общества только в XIX веке, существование этого обычая было зафиксировано только в отдельных районах земного шара.

Рассмотрим сведения, относящиеся к военной культуре хантов. Они содержатся в эпических произведениях - героических песнях, былинах и сказаниях, которые впервые были записаны, а также изучены статским советником Серафимом Кероповичем Паткановым (1860-1918). По его мнению, эпические произведения были составлены хантами до прибытия в Западную Сибирь казаков атамана Ермака, в период с XIV по XVI века [15, с. 86, 89, 91-92; 17, с. 217-218; 18, c. 27]. Многие современные специалисты, занимающиеся изучением Западно-Сибирского фольклора, также полагают, что основная часть сказаний о деяниях богатырей «относятся именно к завершению средневековья и началу русской колонизаиии» [20, с. 83]. Детальное изучение хантыйских эпических произведений позволило А. В. Головнёву и Е. В. Переваловой предположить, что в них следует видеть «...не «былины», а священные сказания, своего рода «жития духов» со свойственными им гротесками, что побуждает воспринимать повествование как священный текст, а не бытовую прозу» [8, с. 117]. Эти сказания посвящены богатырям, которые доживали до глубокой старости и умирали естественной смертью, а не погибали в бою [9, с. 36-37].

Из текстов эпических произведений известно, что в XIV - XVI вв. ханты жили в городках, из-за чего их называли народом городков (хурун ех) [7, с. 112]. Самые ранние городки могли появиться в XIII веке [21, с. 154]. Всего в землях хантов, по сведениям К. С. Патканова, насчитывалось более 100 городков (в Тобольском уезде - не менее 63, и в Березовском - более 40). Друг от друга они находились на расстоянии от 20 до 60 вёрст [15, с. 97, 106 прим. 4]. Названия городков заканчивались на слог - «вош», «воч», «вач», «у Вог», «уш» [15, с. 97, $100 ; 8$, c. 116]. Каждый городок представлял собой резиденцию знати родовой общины, а в случае большой опасности также использовался как временное убежище для её рядовых членов [15, с. $101 ; 17$, с. $224-$ 225]. Родовая община могла иметь и несколько городков, которые ей служили сезонными поселениями [21, с. 154]. В одном случае отряд не превышал 50 человек, а в другом, достигал 300 и даже 700 воинов [8, с. 116]. По-видимому, войско в 300-700 человек включало несколько мелких дружин [24, с. 128]. Власть князя (в былинах - богатыря) на этом этапе общественного развития, скорее всего, была выборной $[10$, c. 95; 16, с. 79]. По определению 3. П. Соколовой, богатыри жили в эпоху «военно-потестарной организации», характеризующейся разложением родовых отношений и зарождением государственной власти «в условиях возрастающей роли войны (межплеменной и с иноэтничными соседями)» [6, с. 370]. Причинами войны, в изложении эпоса, могли стать кровная вражда, различные оскорбления, неудавшееся сватовство, а также нажива $[17$, с. 47,220 ; 7, с. 110-111]. В связи с тем, что большинство эпических произведений были составлены в преддверии русской колонизации, отсутствуют точные данные, когда выборная власть богатырей стала наследственной. Тем не менее, в исторической литературе отмечено, что размеры большинства остяц- 
ких княжеств соответствовали волостям, образованным в составе Тобольской губернии [2, с. 100-101]. На территории каждой волости ханты разговаривали на своём диалекте - казымском, обдорском и т. д. $[10,1968$, с. 95$]$.

Из литературных источников XIV - XVI вв., по утверждению С. К. Патканова, можно выделить только один героический рассказ, в котором засвидетельствованы действия военно-ритуального каннибализма. Этот рассказ он записал в Темлячеевской волости, Тобольского уезда. Перед нами предстаёт образ богатыря Сенгепова, который когда-то жил на месте Больших Атлымских юрт (существовали в XIX веке в Березовском уезде) и регулярно разорял земли по Нижнему Иртышу. В итоге жители разорённых мест решили ему отомстить. Собрав войско и войдя во владения богатыря, они узнали, что Сенгепов умер, и уже покоится в земле. Тогда они пошли на кладбище, выкопали из земли его тело, вырезали из него сердце, разделили сердце на части, и съели. По этому поводу С. К. Патканов пишет: «Этот единичный бакт не имел бы сам по себе значения, как вообше все единичные случаи, если бы о подобных обычаях древних угров не передавали нам и другие исследователи» [16, с. 101-102]. К числу таких исследователей можно отнести и Н. Л. Гондатти. Обобщив данные о богатырях в мансийских сказаниях, он сообщает: «Убив врага, они всегда съедали его сердие и печень, чтобь вся сила убитого перешла к ним, и чтобь он не ожил» [9, с. 36]. Далее он указывает, что эти богатыри говорили по-обски, так как ещё не было мансийского языка ${ }^{1}$, и что они жили отдельными семьями или целыми селениями [9, с. 35-36]. Из этого следует, что знакомство манси с хантыйским эпосом произошло в результате активной инфильтрации хантов в мансийскую среду или, наоборот, из-за миграционных процессов манси на восток. В частности, в преданиях манси Северной Сосьвы и Ляпина сохранились сведения о набегах на их земли «народа городков» [7, с. 112]. Также известно, о движении мансийских племен с запада на восток начиная с конца XVI века в бассейн реки Конды и её притока Карыма. В этих районах они ассимилировали хантов [14, с. 28-29]. К востоку от Конды жили васьюганские (сургутские) ханты, которые также практиковали ритуальный каннибализм. В одном из преданий сообщается: «победитель вырывает у поверженного врага «пахнущее рыбой, много рыьбь съевшее сердие, разрезает его на три части и съедает» [25, с. 163]. По-видимому, эти события относятся к периоду, когда на территории Васюгано-Ваховского района существовало княжество нарымских селькупов - Пегая Орда, окончательно разгромленное ханты в конце XVI - начале XVII века [14, с. 170; 7, с. 115].

В конце XVI - начале XVII вв. хантыйские княжества попали в вассальную зависимость от Московского царства и на их территории были построены остроги: Берёзов (1593), Сургут (1594), Нарым (1598), Кетск (1602), Томск (1604), Маковск (1618) и др. В итоге власть остяцких князей была ограничена [20, с. 97]. Дольше всех независимость сохраняло Кодское княжество. Его ликвидировали в 1644 г. [3, с. 24-25, 40-42; 20, с. 116]. По прибытию на место воеводы не только объявляли «государево жалованное слово», но также должны были держать «ласку и береженье», «тягости... не чинить», «ясаков лишних» не накладывать ${ }^{2}$, чтобы не «ожесточить» и «шатости... не навести» [20, с. 102]. Известно, что в правление Михаила Фёдоровича
1 Первые фиксации отдельных мансийских слов (в основном названий предметов) были сделаны в XVI XVII вв. [29, с. 265].

Ясак - слово тюркского происхождения, буквально означает: закон, устав, уложение. Поэтому, ясаком называет всё, что определено и запрещено законом. Ясаком называли и принудительную подать (дань), установленную победителем [2, c. 95-96]. 
Романова (1613-1645) сибирские воеводы даже вводили в судопроизводство нормы местных обычаев. Так, если один ясачный убивал другого, то он уплачивал не только вознаграждение родственникам убитого, но нередко и годовой ясак, за себя и за убитого. Уплата в государеву казну ясака за себя и убитого продолжалась до тех пор, пока преступник не находил не учтённого ясакоплательщика [5, с. 292].

Неучтённых остяков (ханты), которые бы не платили ясак в государственную казну, было немного. Во-первых, высокая смертность. Рождалось примерно столько же, сколько умирало [14, с. 22]. Так, зимой 1625-1626 гг. в Сургутском уезде был голод: «... ели человечину и собаки, и детишки у многих померли и собаки все примерли ... и от того великого голоду многие ясачные люди, пометав женитек и детишка, разбрелись безвестно» [3, с. 15]. По этой причине, воеводам предписывалось учитывать местную специфику, и поэтому в царской грамоте для нарымского воеводы, датированной декабрем 1644 г., было оговорено, что если ясачный выбывал из списка, то ему нужно было найти замену из окружения родственников, без увеличения списка. На тот момент в Нарымском уезде насчитывалось 238 ясачных людей [6, с. 253]. Во-вторых, злоупотребления чиновников, всевозможные приписки, которые по факту не учтённых ставили в разряд учтённых. Назначенный в 1625 г. сургутским воеводой Н. Е. Пушкин установил, что многие из тех, кого предыдущий воевода И. Р. Безобразов внёс в список, являлись физически немощными, старыми, калеками и несовершеннолетними [6, с. 250-251]. Чтобы внести исправления в ясачные списки по Сургутскому уезду, воевода Н. Е. Пушкин подал в Москву жалобу, по которой было принято решение: «... он, Микита, о том пишет ко государю для своей корысти, чтоб ему ясашным людем полехчить, а в государеве бы ясаке недобор учинить». Поэтому Н. Е. Пушкину было велено собирать ясак по спискам И. Р. Безобразова, а в случае недобора, взыскать плату с товарища по воеводству Белкина, а также самого себя. В итоге в «Ведомости сибирских городов» о задолженности по Сургутскому уезду по состоянию на 1701 г. сказано: «А в доимке за прошлые годы, со 133-го по 208-й год (1625-1700 гг. - Е. Вершинин), 136.533 рубли 5 алтын 4 деньги» [6, с. 250-251].

Временно не уплачивать ясак могли только лица, вовлечённые в миграционный процесс. Причин к миграции было несколько. Это и массовое переселение выходцев из центральных губерний России, и долговая кабала по неуплате ясака, а также процесс принудительной христианизации. В XVII - XVIII вв. ханты в основном мигрировали на север и восток [14, с. 15-16, 22-23]. В итоге некоторым воеводам удавалось существенно увеличить списки ясакоплательщиков. Так, стольник М. С. Лодыженский, находясь на посту Берёзовского воеводы (1647-1650), собрал недоимки по ясаку на 700 рублей за 12 лет и дополнил ясачный список на 406 человек [6, с. 253]. Следовательно, управленческий успех на посту воеводы в Западной Сибири, прежде всего, зависел от местности, в которой проходила государева служба. В середине XIX в. М. А. Кастрен дал характеристику трём группам ханты: 1) иртышские - осёдлые, дома строят в русской традиции, занимаются скотоводством и земледелием, охота и рыболовство имеют второстепенное значение; 2) сургутские - ведут полуосёдлый образ жизни, строят юрты из бревен, торфа и древесной коры, занимаются 
исключительно охотой и рыболовством; 3) обдорские - ведут кочевой образ жизни, живут в чумах, имеют многочисленные стада оленей [11, c. 84].

Во время нападения военного отряда, ответственность за кровопролитие обычно нёс предводитель - хантыйский богатырь. Поэтому политический антагонизм между обычаем хантов вести войны и фискально-ясачными требованиями Москвы был неизбежен. Следовательно, любые междоусобицы остяцких князей расценивались русскими воеводами как измена и «смута». В 1616 г. из Сургута сообщали, что в августе 1616 г. «Кинема сотоварищзи 30 человек государю изменили и приходили на обских остяков тое ж Бардакой волости на аганских, и на аслыпских, и на юганских ясачных остяков, хотели их воевати» [20, с. 97]. Надо полагать, что в первой половине XVII века междоусобицы в землях ханты были прекращены, а военное искусство начало трансформироваться в спортивные мероприятия, исключительной функцией которых стала подготовка охотников. В основу состязаний и игрищ легли соревнования эпохи богатырей: стрельба в цель, прыжки в высоту через натянутые ремни, борьба, бег на лыжах, метание друг в друга каменных глыб с помощью ноги, спихивание друг друга с места, и т. д. [24, с. 126].

Рассмотрев литературные источники, а также определив причины, способствовавшие исчезновению военно-ритуального каннибализма у ханты, рассмотрим наличие этого обычая в культуре ненцев. Известно, что часть угров к середине I тыс. н. э. мигрировала из лесостепных районов Западной Сибири на территорию Нижнего Приобья, а также на запад в Приуралье. На рубеже I - II тыс. н. э., группы угров, которые ранее мигрировали за Урал, начали вновь переселяться, но уже в район Нижнего Приобья. Проникая на север, угры (ханты и манси) захватывали территории лесных ненцев («урех») и вынуждали их покидать свои земли. По данным фольклора, угры, которые пришли с запада, именовали себя «мось», «тэв охаль», «вохаль ев», «пастер ех», а те, которые с юга - «пор», «послан», «похрын», «хурынг ех» $[12$, с. $85 ; 19$, с. $36 ; 8$, с. $117 ; 7$, с. 102]. К группе северных хантов этнографы относят население, проживающее по Оби от Мало-Атлымских юрт до Обдорска, включая население Северной Сосьвы и Ляпина [19, с. 36 прим. 1]. Из преданий известно, что народы «ур-ех» и «мось-ех» продолжительное время конфликтовали, и между ними неоднократно происходили военные столкновения. История этих столкновений отражена в топонимах и гидронимах Ханты-Мансийского округа и на границе Ямало-Ненецкого округа. Так, урочище у юрт Хорпынгорт называется «Ёран ех вилим» (Место битвы с ненцами), у юрт Тиль-тим - «Ляль кертын» (Война назад вернулась). Один из притоков р. Сыни известен как «Ёран ёх вилим юган» (Река, где с ненцами война шла) [7, с. 102; 19, с. 38]. Схожие по смыслу значения имеют и названия нескольких озёр между юртами Мозямы и городом Белоярским. Одно из них, Юрн лор, так было названо, в связи с гибелью ненецкого войска: «Когда ненцев убили, их головы поставили вокруг озера, где не хватило человеческих голов - поставили головы собак». Следующее озеро - Ляль эхт лор, у него ночевали перед сражением. Затем Хэхалмум лор - у этого озера ненцы отступили [23, c. 45]. 
В итоге ненцы признали верховенство ханты. В предании о мире между хантами и ненцами сообщается, что после поражения ненцы поклялись больше не воевать с хантами и кинули жребий, выбрав из своего круга воинов жертву. После этого воин был убит, а тело сварено и съедено. На месте пиршества срубили у лиственницы верхушку, и на обрубок дерева поставили то корыто, из которого ели убитого. По свидетельству коллежского регистратора, заседателя суда в Обдорске Юрия Ивановича Кушелевского (1825-1880) эту лиственницу можно было ещё видеть в середине XIX в. недалеко от Пашерцовых юрт и села Обдорска [13, с. 54]. Скорее всего, ненцы убили своего воина по настоянию хантов, но эта часть рассказа просто утрачена. О развитии событий по такому сценарию косвенно могут свидетельствовать предания, сохранившиеся у других народов: «B данных сюжетах соперник или враг часто предлагает своему антагонисту вкусить мяса или выпить крови его же родственника... Отююда очевидно, что человеческие жертвоприночения представляются ненормальным ритуальным установлением, а актом индивидуальной мести вследствие родовой или семейной распри» [26, с. 286]. Из современных исследователей на это предание ссылается Е. В. Перевалова в вопросе установления долговечного мира между хантами и ненцами [19, с. 38-39]. Впоследствии художник М. С. Знаменский (1833-1892) иллюстрируя книгу Ю. И. Кушелевского «Северный полюс и земля Ямал. Путевые записки» (1868) обратил на этот рассказ внимание и создал рисунок «Мир заключенный между самоедами и остяками, после продолжительной войны» [13, между с. 56-57].

Что касается самых поздних источников, они датированы первой половиной XVIII века. Это донесения Берёзовскому военному коменданту, Берёзовскому воеводе, а также судебные дела Берёзовской канцелярии, которые до середины XIX века хранились в Берёзовском земском суде $[1$, с. 21]. Так вот, Берёзовская воеводская канцелярия в эпоху Петра І вела дело «О набегах самоедов» (опись № 3) [1, с. 21]. В частности, в 1722 г. Берёзовскому воеводе Пашкову было доложено, что группа самоедов (ненцев) численностью 130 человек под руководством Нарта и Питича совершили преступления в Ляпинской волости. Они убили несколько христиан-остяков (хантов) «... и, вырезав, сердца их съели» $[27$, с. 152]. Вероятно, что аналогичные преступления в отношении хантов, принявших христианство, были совершены также в Подгородней и Куноватской волостях под руководством Пунзы Тыровова, Немды Юмина, Харка Лявова и Обынды Хапуева. В литературе их злодеяния подробно не описаны, а лишь сообщается, что в Подгородней волости «... убили князя Никифора Еурова, самого во многих местах копьями изранили и над телом делали поругания. Отсюда отправились в Куноватскую волость, ограбили Нахрачевские и Жижимковские юрты и убили нескольких остяков с обычными поруганиями и варварством» $[27$, с. $152 ; 7$, с. 104]. В основном нападениям подвергалось население волостей, принявшее христианство. Фактически христианизацию ненцы восприняли как войну и поэтому «за поруганиями над телом, рассечением груди, и другим варварством следует видеть не патологическое зверство, а военные традиuии» [7, с. 105]. Ранее религиозные разногласия не являлись причиной для начала объявления войны, по крайней мере, их не упоминает С. К. Патканов, так же как и другие исследователи. Вероятно, ненцы 
просто попытались восстановить свои права на отнятые у них когдато земли. Момент был выбран удачно, ликвидация княжеств и упадок военной культуры у хантов, делали их поселения уязвимыми.

Надо сказать, что территория Берёзовского уезда была обширной, и она формировалась, как и другие северные уезды, с единственной целью - взять под административный контроль как можно больше ясачного населения [6, с. 220]. На востоке границы уезда тянулись вдоль нижнего течения Оби и её притокам: Полую, Куновату, Казыму, Большой Сосьве, Сыне, Войкару, Соби и Щучьей. На севере он граничил с Северным Ледовитым океаном, на востоке - с Тазовской губой, рекой Пур, верховьями реки Лямина, а на юге - Тобольским уездом [5, с. 21]. Но, несмотря на значительные размеры, ясачных людей в уезде в первой четверти XVIII в. насчитывалось всего 1712 человек. Рассмотрим по волостям: в Казымской (216 человек), Обдорской (388 человек), Куноватской (316 человек), Сосвинской (429 человек), Ляпинской (264 человека), Подгородней (99 человек) [4, с. 59]. Если хантов и манси можно было заставить выполнять судебные решения воевод - платить ясак за убитых, то ненцы, вероятно, такие решения просто игнорировали, ведь они кочевали вместе с оленьими стадами.

Поэтому, чтобы прекратить бесчинства, которые совершали ненцы в Березовском уезде, митрополит Филофей Лещинский обратился в Тобольске к администрации, с просьбой защитить хантов [1, с. 21]. 19 июня 1725 г. было велено Березовскому воеводе принять меры по охране остяцких (хантыйских) волостей [1, с. 21]. В том же году из среды знатных ненцев были взяты в Берёзов аманаты (заложники - для принуждения сородичей платить ясак) [1, с. 21; 27, с. 153; 7, c. 108]. Но этих мер было недостаточно. Когда на престол взошла Анна Иоановна, она велела в 1730 г. с целью защиты новокрещённых инородцев направить в волости - Обдорскую, Сосвинскую, Ляпинскую, Назымскую, а также в городок Юильский - группы казаков, и построить в них остроги [27, с. 153, 155]. В 1744 г. по итогам следствия упомянутые ненцы (самоеды) Пунза Тыровов и Немда Юмин были повешены в Обдорске, Харка Лявов - в Казыме, а Обындя Хапуев - в Ляпинском городке. Судьба Нарта и Питича не известна. Последнее упоминание, когда берёзовские ненцы во главе с Евой Ледовым убили хантыйского князца Никифора Чурова и «грудь вспороли и прочие непотребности чинили» (надо полагать вырезали сердце и съели), датировано 1748 годом [7, с. 105]. Более поздних фактов, которые бы свидетельствовали о применении военно-ритуального каннибализма ненцами, в литературе не выявлено [27, с. 152]. Следовательно, набеги ненцев на поселения крещённых хантов и манси должны были прекратиться в правление Елизаветы Петровны (1741-1761). В частности, в 1745 г. в Обдорске началось строительство деревянной православной церкви, которая была освещена в 1751 году, а в 1806 г. по указанию Тобольского губернатора А. М. Корнилова был разобран из-за ветхости и Обдорский острог [27, с. 164, 177].

В статье не рассмотрена тема применения коренным населением Западной Сибири ритуального каннибализма в быту, хотя, как было сказано, военно-ритуальная практика восходит к религиозным воззрениям родовой общины. По утверждению С. В. Бахрушина, ханты в древние времена практиковали человеческие жертвоприношения и для этой цели использовали рабов. В качестве одной такой жертвы 
упомянут «купленный самоедский малый». Источников рабства было два: война и купля-продажа $[3$, с. 14, 24]. Как было сказано, ханты прекратили междоусобицы и военные конфликты в XVII в., но это не означает, что исчезла и работорговля. Также не ясно, в каких случаях человека приносили в жертву. Какому божеству посвящали жертву? Что делали с жертвой? На какой территории расселения хантов проводили обряд - иртышских, сургутских, обдорских или на всех трёх? На эти вопросы частично можно ответить, проведя параллель с аналогичным обычаем, существовавшим у пелымских манси. Когда-то в окрестностях Пелыма находилось святилище со священной лиственницей. Это дерево манси украшали не только серебром и золотом, но приносили ей и человеческие жертвы, и в 1618 г. «малого убили» [3, c. 26]. Вероятно, что большинство историй с жертвоприношениями в быту на территории расселения хантов и манси происходили до начала миссионерской деятельности Фелофея Лещинского (1710-1725), который уничтожил практически все языческие святилища, и распространил христианство на территории Западной Сибири. Исключение тогда составила Обдорская волость, христианизация в которой проводилась уже во второй половине XVIII века.

Из эпического сказания «Подросток», записанного в Ненецком национальном округе, известно, что в жертву хотели принести мальчика. Названо жертвенное место - «Нохо» и частично дано описание ритуального действия: «Я поднимусь на сопку, чтобы сварить пищу приносящим жертву. Тебе на шею накинут веревку... Носитэта дернул меня за руку. На шею накинул веревку. Один раз дернули веревку. У меня (мальчик из рода Хоратэта) потемнело в глазах, но потом я пришел в себя. Второй раз дернули» [22, с. 555-556]. В жертву приносили и стариков, но только по их желанию. Так, Ю. И. Кушелевский (1825-1880), ссылаясь на ненецкие предания, повествует, что когда-то пожилые люди - ненцы, которые уже не способны были заниматься охотой и ездить на оленях, приказывали убить себя «в честь счастливой жизни своего потомства, а тело свое съесть». Это повествование Ю. С. Кушелевский не датировал, но он сообщает, что в 1840-х годах в тобольских арестантских ротах содержался ненец, за аналогичное преступление [13, с. 52-53; 28, с. 246-247].

Выводы. В статье рассмотрен военно-ритуальный каннибализм, который практиковался в военных обычаях хантов и ненцев Западной Сибири. Он являлся неотъемлемой частью ведения войны. Сохранившиеся эпические произведения хантов не дают нам возможности представить полную картину использования этого обряда, когда междоусобные войны считались нормой. В то же время, в эпоху Русского государства династии Романовых, этот обычай в письменных источниках уже не фиксируется. Это обстоятельство позволило автору предположить, что искоренение ритуального каннибализма в военной культуре хантов связано с методами экономического воздействия - ясаком. Преступник должен был платить ясак и за себя, и за убитого, что обрекало виновного на нищенское существование. Фактически междоусобные войны, которые ранее вели хантыйские князья, Русское государство объявило уголовным преступлением. Поэтому исчезновение ритуального каннибализма в военных обычаях хантов, напрямую связано с прекращением междоусобных войн, а этого удалось добиться не ранее второй четверти первой полови- 
ны XVII века. Предлагаемая датировка является обобщённой, так как уровень культуры князей иртышской зоны расселения, сургутской и обдорской, контактировавших с татарской, а позже русской администрацией был разным. По этой причине некоторые князья даже в условиях ведения войны могли рассматривать ритуальный каннибализм уже как пережиток.

Что касается ненцев, то у них ритуальный каннибализм во время ведения военных действий практиковался как минимум до середины XVIII века. Именно этим временем датируются последние из выявленных сведений о его применении в зоне их расселения. В отличие от хантов, сбор ясака с ненцев осуществлялся номинально. Количество ясачных подданных было трудно определить, поэтому верили старейшинам на слово. Чтобы как-то усмирить ненцев или «каменскую самоядь», а именно так названы ненцы района Оби в «Сказании о человецех незнаемых в восточной стране» (литературный памятник конца XV - начала XVI вв.), государство построило на разграничении земель ненцев и хантов в Березовском уезде остроги. Фактически остроги отделили землю, которую государство могло административно контролировать, от территории, которую государство контролировало номинально. Ведь уменьшение ясачного населения во время военных столкновений между язычниками ненцами, а также христианами хантами и манси несло угрозу экономической стабильности государства, подрывало веру в могущество Православной церкви и государя. К тому же Российская империя в то время ещё не имела своих сереброплавильных заводов (Колывано-Воскресенский сереброплавильный завод будет открыт лишь в 1744 году), и поэтому государство за меха и пушнину покупало для казны золото и серебро.

Указанные хронологические рамки также позволяют дать комментарий и сделать уточнения к карте мира распространения антропофагии «Die Verbreitung der Anthropophagie», которая была издана в Германии в 1893 г. П. Бергеманом. На этой карте в пределах всей Российской империи только Западная Сибирь от реки Обь до реки Енисей показана как место, где в историческом прошлом был распространён каннибализм. К тому же вся отмеченная территория названа почему-то «OSTJAKEN», хотя на территории Западной Сибири проживали и проживают не только ханты (ранее остяки), но также такие коренные народы, как манси, ненцы и селькупы. К тому же в культуре хантов и манси, которые граничат с ненцами на севере, ритуальний каннибализм исчез раньше, а территория ненцев на антропологической карте вообще не обозначена

\section{Литература}

1. Абрамов Н. О введении христианства у березовских остяков // Журнал министерства народного просвещения. 1851. № 12. C. 1-22.

2. Бахрушин С. В. Ясак в Сибири в XVII в. // Сибирские огни. 1927. № 3. С. 95129.

3. Бахрушин С. В. Остяцкие и вогульские княжества в XVI - XVII вв. Л.: Изд- во Института народов Севера ЦИК СССР, 1935. $91 \mathrm{c.}$

4. Буцинский П. Крещение остяков и вогулов при Петре Великом. Харьков: Типография губернского правления, 1893. $93 \mathrm{c}$.

5. Буцинский П. Н. Сочинения в двух томах: Т. 1. Заселение Сибири и быт первых ее насельников / Под ред. С. Г. Пархи- 
мовича. Сост. Ю. Л. Мандрика. Тюмень: Изд-во Ю. Мандрики, 1999. 328 с.

6. Вершинин Е. В. Русская колонизация Северо-Западной Сибири в конце XVI - XVII вв. Екатеринбург: Демидовский институт, 2018. 504 с.

7. Головнев А. В. Говорящие культуры: традиции самодийцев и угров. Екатеренбург: УрО РАН, 1995. 607 с.

8. Головнев А. В., Перевалова Е. В. Вожди обских угров и ненцев (по данным фольклора) // Вестник Томского государственного университета. История. 2017. № 49. С. 115-122.

9. Гондатти Н. Л. Следы язычества у инородцев Северо-Западной Сибири. М.: Типография Е. Г. Потапова, 1888. 91 с.

10. История Сибири. Сибирь в составе феодальной России. Т. 2 // История Сибири в 5-ти томах. Ленинград: Наука, 1968. $539 \mathrm{c}$.

11. Кастрен М. А. Сочинения в двух томах: Т. 2. Путешествие в Сибирь (18451849) / Под ред. С. Г. Пархимовича. Сост. Ю. Л. Мандрика. Коммент. А. П. Зенько и С. Г. Пархимовича. Тюмень: Изд-во Ю. Мандрики, 1999. 352 с.

12. Кашлатова Л. В. Феномен женских божеств в культуре среднеобских хантов (к постановке вопроса) // Вестник угроведения. 2015. № 1 (20). С. 84-88.

13. Кушелевский Ю. И. Северный полюс и земля Ямал. Путевые записки. СПб.: Типография М. В. Д., 1868. 160 с.

14. Мартынова Е. П. Очерки истории и культуры хантов. М.: Изд-во Институт этнологии и антропологии РАН, 1998. 236 с.

15. Патканов С. К. Стародавняя жизнь остяков и их богатыри, по былинам и сказаниям // Живая старина. Вып. III. СПб.: Типография С. Н. Худякова, 1891. С. 85-116

16. Патканов С. К. Древняя жизнь остяков и их богатыри, по былинам и сказаниям // Живая старина. Вып. IV. СПб.: Типография С. Н. Худякова, 1891. С. 67-108.

17. Патканов С. К. Сочинения в двух томах: Т. 1. Остяцкая молитва / Под ред. С. Пархимовича; Сост. и вступ. статья Ю. Мандрики; Пер. Е. Матюхиной; Коммент. С. Пархимовича. Тюмень: Изд-во Ю. Мандрики, 1999. 400 с.

18. Патканов С. К. Сочинения в двух томах: Т. 2. История колонизации Сибири / Под ред. С. Пархимовича; Сост. Ю. Л. Мандрика. Тюмень: Изд-во Ю. Мандрики, 1999. $320 \mathrm{c}$.

19. Перевалова Е. В. Войны и миграции северных хантов (по материалам фольклора) // Уральский исторический вестник (Древние и средневековые культуры Урала в евразийском культурном пространстве). Екатеринбург: Академкнига, 2002. С. 3658.

20. Перевалова Е. В., Карачаров К. Г. Река Аган и ее обитатели. Екатеринбург, Нижневартовск: УРО РАН, Студия «Графо», 2006. $352 \mathrm{c}$.

21. Перцев Н. В. Аборигенные городки Нижнего Приобья XV - XVI вв. Торговый аспект // Вестник Томского государственного университета. 2018. № 426. С. 154-158.

22. Подросток // Эпические песни ненцев. М.: Наука, 1965. С. 554-565.

23. Пятникова Т. Р. Героические сказания хантов в современных условиях // Матлы VI Югорских чтений «Героический эпос обских угров: наследие и современность». Сб. науч. ст. / Под ред. К. В. Афанасьевой. Т. В. Волдиной. М.: Изд-во «ИКАР», 2005. С. 39-46.

24. Соловьев А. И. Военное дело коренного населения Западной Сибири. Эпоха средневековья. Новосибирск: Наука, 1987. $193 \mathrm{c}$.

25. Сподина В. И. Мировоззренческие установки в описании телесно-психического состояния человека в традиционной культуре обских угров и самодийцев // Вестник угроведения. История. Этнография. Археология. 2011. № 1. С. 161-167.

26. Хренов Н. А. Застолье в контексте ритуала // Традиционное русское застолье: сб. ст. М.: Гос. респ. центр русского фольклора, 2008. С. 272-293.

27. Шемановский И. С. Хронологический обзор достопамятных событий в Березовском крае Тобольской губернии (1032-1910 гг.) // Избранные труды. Т. 1. М.: Советский спорт, 2011. С. 107-292.

28. Юнина М. В. К вопросу о существовании в прошлом человеческих жертвоприношений и каннибализма у ненцев // Самодийцы. Мат-лы IV сибирского симп. «Культурное наследие народов Западной 
Сибири» (10-12 декабря 2001 г., Тобольск). Тобольск-Омск: ОмГПУ, 2001. С. 246-249.

29. Язык и общество. Энциклопедия. М.: Изд. центр «Азбуковник», 2016. 872 с.
30. Bergemann P. Die Verbreitung der Anthropopfagie iiber die Erde und Ermittelung einiger Wesensziige dieses Brauches. Bunzlau. 1893.

\section{Aleksandr E. VOLF,}

Ph. D. (in History), Senior Researcher, Department of Modern History, The Shemanovsky Museum-Exhibition Complex (Salekhard, Russia).

E-mail: wolf424@mail.ru

\section{On the Issue of the Disappearance of Ritual Cannibalism in the Military Culture of the Indigenous Peoples of Western Siberia}

The article considers the question of eradicating from the military culture, military culture of the Ostyaks (Khanty) and Samoyeds (Nenets) military ritual of Western Siberia, such a custom as ritual cannibalism. The cannibalism, analysis of literary sources showed that the Ostyaks (Khanty) epic, stopped using it in the first half of the 17th century, and the hero, Samoyeds (Nenets) - no earlier than the middle of the 18th century. The withering away of this custom is connected with the introduction by the Russian state of a yasak (tribute) policy in khanty, Western Siberia, and with the announcement of the instigators of yasak, civil strife as sovereign traitors. This measure, the construction voivode, of forts, as well as the beginning of Christianization, made it Western Siberia, possible to establish a relative peace in the northern regions of Russian state Western Siberia

For citation: Volf A. E. On the Issue of the Disappearance of Ritual Cannibalism in the Military Culture of the Indigenous Peoples of Western Siberia // Oriental Institute Journal. 2021. № 1. P. 37-48. DOI https://doi. org/10.24866/2542-1611/2021-1/37-48

\section{References}

1. Abramov N. O vvedenii khristianstva u berezovskikh ostyakov // ZHurnal ministerstva narodnogo prosveshheniya. 1851. № 12. S. 1-22.

2. Bakhrushin S. V. YAsak v Sibiri v XVII v. // Sibirskie ogni. 1927. № 3. S. 95-129.

3. Bakhrushin S. V. Ostyatskie i vogul'skie knyazhestva v XVI - XVII vv. L.: Izd-vo Instituta narodov Severa TSIK SSSR, 1935. $91 \mathrm{~s}$.

4. Butsinskij P. Kreshhenie ostyakov i vogulov pri Petre Velikom. KHar'kov: Tipografiya gubernskogo pravleniya, 1893. $93 \mathrm{~s}$.

5. Butsinskij P. N. Sochineniya v dvukh tomakh: T. 1. Zaselenie Sibiri i byt pervykh ee nasel'nikov / Pod red. S. G. Parkhimovicha. Sost. Yu. L. Mandrika. Tyumen': Izd-vo Yu. Mandriki, 1999. 328 s.

6. Vershinin E. V. Russkaya kolonizatsiya Severo-Zapadnoj Sibiri v kontse XVI - XVII vv. Ekaterinburg: Demidovskij institut, 2018. $504 \mathrm{~s}$.

7. Golovnev A. V. Govoryashhie kul'tury: traditsii samodijtsev i ugrov. Ekaterenburg: UrO RAN, 1995. 607 s.

8. Golovnev A. V., Perevalova E. V. Vozhdi obskikh ugrov i nentsev (po dannym fol'klora) // Vestnik Tomskogo gosudarstvennogo universiteta. Istoriya. 2017. 
№ 49. S. 115-122.

9. Gondatti N. L. Sledy yazychestva u inorodtsev Severo-Zapadnoj Sibiri. M.: Tipografiya E. G. Potapova, 1888. 91 s.

10. Istoriya Sibiri. Sibir' v sostave feodal'noj Rossii. T. 2 // Istoriya Sibiri v 5-ti tomakh. Leningrad: Nauka, 1968. 539 s.

11. Kastren M. A. Sochineniya v dvukh tomakh: T. 2. Puteshestvie v Sibir' (18451849) / Pod red. S. G. Parkhimovicha. Sost. Yu. L. Mandrika. Komment. A. P. Zen'ko i S. G. Parkhimovicha. Tyumen': Izd-vo Yu. Mandriki, 1999. 352 s.

12. Kashlatova L. V. Fenomen zhenskikh bozhestv v kul'ture sredneobskikh khantov (k postanovke voprosa) // Vestnik ugrovedeniya. 2015. № 1 (20). S. 84-88.

13. Kushelevskij Yu. I. Severnyj polyus i zemlya YAmal. Putevye zapiski. SPb.: Tipografiya M. V. D., 1868. 160 s.

14. Martynova E. P. Ocherki istorii i kul'tury khantov. M.: Izd-vo Institut ehtnologii i antropologii RAN, 1998. 236 s.

15. Patkanov S. K. Starodavnyaya zhizn' ostyakov i ikh bogatyri, po bylinam i skazaniyam // ZHivaya starina. Vyp. III. SPb.: Tipografiya S. N. KHudyakova, 1891. S. 85116

16. Patkanov S. K. Drevnyaya zhizn' ostyakov i ikh bogatyri, po bylinam i skazaniyam // ZHivaya starina. Vyp. IV. SPb.: Tipografiya S. N. KHudyakova, 1891. S. 67108.

17. Patkanov S. K. Sochineniya v dvukh tomakh: T. 1. Ostyatskaya molitva / Pod red. S. Parkhimovicha; Sost. i vstup. stat'ya Yu. Mandriki; Per. E. Matyukhinoj; Komment. S. Parkhimovicha. Tyumen': Izd-vo Yu. Mandriki, 1999. 400 s.

18. Patkanov S. K. Sochineniya V dvukh tomakh: T. 2. Istoriya kolonizatsii Sibiri / Pod red. S. Parkhimovicha; Sost. Yu. L. Mandrika. Tyumen': Izd-vo Yu. Mandriki, 1999. 320 s.

19. Perevalova E. V. Vojny i migratsii severnykh khantov (po materialam fol'klora) // Ural'skij istoricheskij vestnik (Drevnie i srednevekovye kul'tury Urala v evrazijskom kul'turnom prostranstve). Ekaterinburg: Akademkniga, 2002. S. 36-58.
20. Perevalova E. V., Karacharov K. G. Reka Agan i ee obitateli. Ekaterinburg, Nizhnevartovsk: URO RAN, Studiya "Grafo», 2006. 352 s.

21. Pertsev N. V. Aborigennye gorodki Nizhnego Priob'ya XV - XVI vv. Torgovyj aspekt // Vestnik Tomskogo gosudarstvennogo universiteta. 2018. № 426. S. 154-158.

22. Podrostok // EHpicheskie pesni nentsev. M.: Nauka, 1965. S. 554-565.

23. Pyatnikova T. R.

Geroicheskie skazaniya khantov $\mathrm{V}$ sovremennykh usloviyakh // Mat-ly VI YUgorskikh chtenij "Geroicheskij ehpos obskikh ugrov: nasledie i sovremennost'». Sb. nauch. st. / Pod red. K. V. Afanas'evoj. T. V. Voldinoj. M.: Izd-vo «IKAR», 2005. S. 39-46.

24. Solov'ev A. I. Voennoe delo korennogo naseleniya Zapadnoj Sibiri. EHpokha srednevekov'ya. Novosibirsk: Nauka, 1987. 193 s.

25. Spodina V. I. Mirovozzrencheskie ustanovki v opisanii telesno-psikhicheskogo sostoyaniya cheloveka v traditsionnoj kul'ture obskikh ugrov i samodijtsev // Vestnik ugrovedeniya. Istoriya. EHtnografiya. Arkheologiya. 2011. № 1. S. 161-167.

26. KHrenov N. A. Zastol'e v kontekste rituala // Traditsionnoe russkoe zastol'e: sb. st. M.: Gos. resp. tsentr russkogo fol'klora, 2008. S. 272-293.

27. SHemanovskij I. S. KHronologicheskij obzor dostopamyatnykh sobytij V Berezovskom krae Tobol'skoj gubernii (1032-1910 gg.) // Izbrannye trudy. T. 1. M.: Sovetskij sport, 2011. S. 107-292.

28. YUnina M. V. K voprosu o sushhestvovanii v proshlom chelovecheskikh zhertvoprinoshenij i kannibalizma u nentsev // Samodijtsy. Mat-ly IV sibirskogo simp. «Kul'turnoe nasledie narodov Zapadnoj Sibiri»(10-12 dekabrya 2001 g., Tobol'sk). Tobol'sk-Omsk: OmGPU, 2001. S. 246-249.

29. YAzyk i obshhestvo. EHntsiklopediya. M.: Izd. tsentr «Azbukovnik», 2016. 872 s.

30. Bergemann P. Die Verbreitung der Anthropopfagie iiber die Erde und Ermittelung einiger Wesensziige dieses Brauches. Bunzlau. 1893. 